\title{
Daidzein ameliorated concanavalin A-induced liver injury through the Akt/GSK-3ß/Nrf2 pathway in mice
}

\author{
Shang-Lin $\mathrm{Li}^{1}$, Rui Cao ${ }^{1}$, Xiao-Fan $\mathrm{Hu}^{1}$, Peng Xiong ${ }^{2}$, Guang-Yuan Zhao ${ }^{1}$, Ya-Nan Xie ${ }^{1}$, Zhi-Min Wang ${ }^{3}$, \\ Ya-Kun Li ${ }^{1}$, Bo Yang ${ }^{1}$, Jun Yang ${ }^{1}$ \\ ${ }^{1}$ Institute of Organ Transplantation, Tongji Hospital, Tongji Medical College, Huazhong University of Science and Technology, Wuhan, China; \\ ${ }^{2}$ Department of Intensive Care Unit, The Central Hospital of Wuhan, Tongji Medical College, Huazhong University of Science and Technology, \\ Wuhan, China; ${ }^{3}$ Department of Pediatrics, Tongji Hospital, Tongji Medical College, Huazhong University of Science and Technology, Wuhan, \\ China \\ Contributions: (I) Conception and design: SL Li, B Yang; (II) Administrative support: ZM Wang, YK Li; (III) Provision of study materials: XF Hu, J \\ Yang; (IV) Collection and assembly of data: P Xiong, GY Zhao, YN Xie; (V) Data analysis and interpretation: SL Li, R Cao; (VI) Manuscript writing: \\ All authors; (VII) Final approval of manuscript: All authors. \\ Correspondence to: Jun Yang; Bo Yang. Institute of Organ Transplantation, Tongji Hospital, Tongji Medical College, Huazhong University of Science \\ and Technology, Jiefang Road No. 1095, Wuhan 430030, China. Email: jy@tjh.tjmu.edu.cn; yangbo@tjh.tjmu.edu.cn.
}

Background: Daidzein is a soybean isoflavone that has been shown in previous studies to have antiinflammatory and antioxidant effects. However, it remains unknown whether daidzein plays a protective role against concanavalin $\mathrm{A}$ (Con $\mathrm{A})$-induced autoimmune hepatitis (AIH).

Methods: In this study, an animal model of AIH was constructed by intravenous injection of Con A $(15 \mathrm{mg} / \mathrm{kg})$. Daidzein $(200 \mathrm{mg} / \mathrm{kg} / \mathrm{d})$ was intraperitoneally administered to mice for 3 days before the Con A injection. Alpha mouse liver 12 (AML-12) cells were incubated in the absence or presence of daidzein to determine whether daidzein can alleviate Con A-induced hepatotoxicity.

Results: The findings showed that pretreatment with daidzein significantly reduced Con A-induced oxidative stress and hepatocyte apoptosis in Con A-induced liver injury. Pretreatment with daidzein significantly prevented the decrease of intrahepatic protein levels of phosphorylated Akt (p-Akt), phosphorylated GSK3 $\beta$ (p-GSK3 $\beta$ ), nuclear factor erythroid 2-related factor 2 (Nrf2), heme oxygenase-1 (HO-1), and NOQ1 (NAD(P)H quinone dehydrogenase 1) in response to Con A administration. Meanwhile, malondialdehyde (MDA) production was reduced, and glutathione peroxidase (GPX), superoxide dismutase (SOD) activity, and SOD2 mRNA expression were elevated in daidzein-pretreated livers. In in vitro experiments, daidzein pretreatment prevented Con A-induced murine hepatocyte death. This effect was partly diminished by an inhibitor of the phosphatidylinositol 3-kinase (PI3K)/Akt pathway.

Conclusions: These results indicate that daidzein pretreatment attenuates Con A-induced liver injury through the Akt/GSK3 $\beta / \mathrm{Nrf2}$ pathway. Our findings provide new insights into the use of plant-derived products for $\mathrm{AIH}$ treatment beyond immunosuppression.

Keywords: Daidzein; autoimmune hepatitis (AIH); concanavalin A; Akt/GSK3ß pathway; apoptosis

Submitted Feb 09, 2021. Accepted for publication Jun 22, 2021.

doi: $10.21037 / \mathrm{atm}-21-378$

View this article at: https://dx.doi.org/10.21037/atm-21-378 


\section{Introduction}

Autoimmune hepatitis (AIH) is a chronic inflammatory disease characterized by liver parenchymal injury and inflammatory cell infiltration and occurs in individuals of all ages and races, although more frequently in women than men (1). AIH can eventually result in liver cirrhosis and liver cancer, and about $50 \%$ of patients with severe $\mathrm{AIH}$ die within approximately 5 years if no treatment is provided (2). The etiology of AIH remains unclear. A variety of factors, including genetic and environmental factors, are associated with the morbidity of AIH (3). T cells are considered the primary pathogenic immune cells that mediate the occurrence of AIH (4). Although significant progress has been made in understanding AIH pathogenesis, the lack of effective treatments remains a serious issue (5).

Concanavalin A (Con A)-induced acute hepatitis in mice is a well-characterized model for studying $\mathrm{AIH}$ pathogenesis (6). There are two primary mechanisms by which Con A induces liver injury (7-11). Predominantly, it is believed that the aberrant activation of $\mathrm{T}$ cells leads to an abnormal immune response against hepatocytes and the secretion of inflammatory cytokines such as tumor necrosis factor (TNF)- $\alpha$, interleukin (IL)-6, IL-10, and interferon (IFN)- $\gamma$ (7-9). In addition to its T cell-stimulating property, Con A can directly induce hepatic parenchymal cell death $(10,11)$. A previous study revealed that the phosphatidylinositol 3-kinase (PI3K)/Akt signaling pathway plays an important role in Con A-induced liver injury (12). PI3K/Akt pathway activation protects against Con A-induced hepatocyte death by increasing the protein expression of downstream nuclear factor erythroid 2-related factor 2 (Nrf2) and regulating endogenous antioxidant enzymes to resist various oxidative stresses (13). Therefore, regulating the PI3K/Akt signaling pathway can mitigate Con A-induced hepatocyte death by reducing oxidative stress levels.

Daidzein is an isoflavone belonging to a large family of compounds synthesized by plants and has been shown to have anti-inflammatory, antioxidant, and antitumor functions (14-18). Daidzein has been reported to be a specific inhibitor of Caveolin-1 (Cav-1) and thus involved in the regulation of downstream PI3K/Akt signal transduction $(19,20)$. Moreover, daidzein and its derivatives have been found to ameliorate nonalcoholic fatty liver and D-galactosamine- and lipopolysaccharide (LPS)-induced liver failure in mice $(21,22)$. All the evidence indicates that daidzein plays a hepatic protective role. However, little is known about its protective potential in Con A-induced liver injury. Herein, we hypothesized that daidzein regulates the PI3K/Akt/GSK3 $\beta$ signaling pathway in the liver, thereby regulating the expression of $\mathrm{Nrf} 2$, exerting antioxidative functions, and reducing Con A-induced liver injury. We present the following article following the ARRIVE reporting checklist (available at https://dx.doi.org/10.21037/ atm-21-378).

\section{Methods}

\section{Reagents and antibodies}

Daidzein was purchased from Chengdu Pufei De Biotech Co. Mouse 1× Lymphocyte Separation Medium was obtained from Dakewe Biotech Co., Ltd. Concanavalin A type IV (C2010) and Cell Counting Kit-8 (CCK-8) were purchased from Sigma-Aldrich. Carboxy-fluorescein diacetate succinimidyl ester (CFSE) was purchased from Invitrogen (Thermo Fisher Scientific), and the PI3K inhibitor LY294002 was purchased from MedChemExpress (MCE, USA). The following monoclonal antibodies (mAbs) used for cell surface marker staining were purchased from BioLegend: APC-conjugated anti-mouse CD3 (17A2), BV510-conjugated anti-mouse CD4 (GK1.5), FITCconjugated anti-mouse CD8 (53-6.7) and PE-Cy7conjugated anti-mouse CD69 (H1.2F3). Cytokines in serum or culture supernatants were measured using a cytometric bead array (CBA)-based mouse Th1/Th2/Th17 Cytokine Kit (BD Biosciences).

\section{Animals and experimental design}

Male C57BL/6J (B6) mice (8-10 weeks old, 20-24 g) were purchased from Beijing HFK Bioscience (China). All mice were housed under specific pathogen-free (SPF) conditions and allowed free water and food access. In this study, all procedures involving animals were performed and monitored in compliance with the guidelines of Tongji Animal Use Regulations and approved by the Institutional Animal Care and Use Committee (IACUC) of Tongji Medical College (number TJH-201902003).

Con A was dissolved in pyrogen-free phosphate-buffered saline (PBS) and intravenously injected at $15 \mathrm{mg} / \mathrm{kg}$ to induce liver injury. Daidzein $(200 \mathrm{mg} / \mathrm{kg}$ dissolved in saline solution) was intraperitoneally administered to mice for 3 days before the Con A injection. Mice were injected with Con A $1 \mathrm{~h}$ after the last daidzein injection. Mice were randomly divided into four groups ( $\mathrm{n}=6$ each group): 
(I) Control group: mice were treated with saline solution only;

(II) Daid group: mice were treated with daidzein only;

(III) Con A group: mice were injected with Con A at a dose of $15 \mathrm{mg} / \mathrm{kg}$;

(IV) Con A + Daid group: mice were treated with daidzein $(200 \mathrm{mg} / \mathrm{kg})$ three days before Con A injection $(15 \mathrm{mg} / \mathrm{kg})$.

All mice were sacrificed at $12 \mathrm{~h}$ after Con A injection using anesthesia with $1 \%$ pentobarbital $(10 \mathrm{~mL} / \mathrm{kg})$. Serum and liver tissues were harvested and stored at $-80^{\circ} \mathrm{C}$.

For the survival assay, mice ( $\mathrm{n}=10$ each group) were injected with a lethal dose of Con A $(25 \mathrm{mg} / \mathrm{kg})$, with or without daidzein $(200 \mathrm{mg} / \mathrm{kg} /$ day $)$ pretreatment, and mortality was evaluated within $72 \mathrm{~h}$.

\section{Cell viability assay}

Alpha mouse liver 12 (AML-12) cells (5,000 cells/well) were plated in 96-well plates in RPMI-1640 media supplemented with $10 \%$ fetal bovine serum (FBS), $100 \mathrm{IU} / \mathrm{mL}$ penicillin, and $100 \mathrm{mg} / \mathrm{mL}$ streptomycin, and incubated at $37^{\circ} \mathrm{C}$ in a humidified $5 \% \mathrm{CO}_{2}$ incubator. The cells were pretreated with daidzein $(20,40,80,120 \mu \mathrm{m})$ for $6 \mathrm{~h}$, treated with Con A $(10 \mu \mathrm{g} / \mathrm{mL})$, and then cultured for $12 \mathrm{~h}$. To determine whether the activation of the PI3K/Akt signaling pathway in response to daidzein was responsible for Con A-induced hepatotoxicity, AML-12 cells were pretreated with or without the PI3K inhibitor LY294002 (20 $\mu \mathrm{M})$ and then incubated in the absence or presence of daidzein. The viability of AML-12 cells was measured by using a CCK-8 assay according to the manufacturer's instructions.

\section{Flow cytometry analysis of apoptosis}

Further observation of apoptosis was performed using an Annexin V-FITC/PI apoptosis detection kit (MULTI SCIENCES). After treatment with different reagents, AML-12 cells were collected and washed twice with cold PBS, stained with Annexin V-FITC and PI according to the manufacturer's instructions. Both early- and late apoptotic cells were defined as apoptotic cells in this study. Data analysis was performed using FlowJo software (Tree Star).

\section{Serum transaminase assessment}

Blood samples were collected $12 \mathrm{~h}$ after Con A injection, and serum was isolated by centrifugation. Alanine aminotransferase (ALT) and aspartate aminotransferase (AST) levels were measured using a BS-200 automatic biochemical analyzer (Mindray, Shenzhen, China).

Measurement of superoxide dismutase (SOD), glutathione peroxidase (GPX), and malondialdehyde (MDA) in liver tissues

Liver tissues were homogenized and dissolved in extraction buffer, and the SOD, GPX, and MDA levels in liver tissues were measured by SOD detection kits, GPX detection kits, and MDA detection kits, according to the manufacturer's instructions. All of the above kits were obtained from Nanjing Jiancheng Bioengineering Institute.

\section{Immunofluorescence staining}

Liver sections were stained with primary antibody (anticleaved caspase-3) according to the manufacturer's instructions (Servicebio, China). Apoptotic cells were evaluated using a terminal deoxynucleotidyl transferase (TdT) dUTP nick-end labeling (TUNEL) assay kit (Roche Applied Science), according to a standard protocol.

\section{Detection of liver ROS activation}

Dihydroethidium (DHE) fluorescence was used to test the ROS levels in the liver tissues. The fresh liver tissues were stored in ethanol and dry ice at $-80^{\circ} \mathrm{C}$. Sections with a thickness of $5 \mu \mathrm{m}$ were obtained, the liver cryosections were then incubated with DHE $(10 \mu \mathrm{mol} / \mathrm{L})$ for $60 \mathrm{~min}$ in the dark and then washed with PBS. Upon oxidation, DHE exhibits red fluorescence. The images were captured using a fluorescence microscope at 200x magnification, and the fluorescence intensities were quantified on Image-pro plus 6.0.

\section{Cytokine assay}

The levels of IFN- $\gamma$, TNF- $\alpha$, IL-2, IL-6, IL-10, and IL17 in serum $12 \mathrm{~h}$ after Con A challenge, or in culture supernatants $72 \mathrm{~h}$ after stimulation, were examined with a CBA Mouse Th1/Th2/Th17 Cytokine Kit according to the manufacturer's protocols.

\section{Hepatic mononuclear cell (MNC) isolation and flow cytometry}

MNCs were isolated, as described by Watarai et al. (23). 
Each mouse liver was perfused with Hank's balanced salt solution to eliminate blood until the liver became pale. Liver tissues were removed and ground through a 70- $\mu \mathrm{m}$ cell strainer (BD, USA). Cell suspensions were then collected and purified by density gradient centrifugation in a $38 \%$ Percoll solution (GE Healthcare, USA). Purified splenocytes were prepared by homogenization with a syringe, followed by passage through a $0.1-\mathrm{mm}$ sterile nylon mesh and erythrocyte depletion. The cells were then stained with antibodies against the indicated surface markers, including CD3, CD4, CD8, and CD69. Finally, the cells were examined by a FACSCelesta (BD Biosciences) and analyzed with FlowJo software (Tree Star).

\section{Proliferation assay}

Splenocytes from B6 mice were harvested according to Liu et al. (24). Purified splenocytes were resuspended in RPMI1640 medium and labeled with $2 \mu \mathrm{mol} / \mathrm{L}$ CFSE for $5 \mathrm{~min}$ in a $37^{\circ} \mathrm{C}$ incubator in the dark. Splenocytes were then seeded at $2 \times 10^{5}$ cells/well in 96-well plates with $200 \mu \mathrm{L}$ RPMI-1640 medium containing $10 \%$ FBS plus daidzein $(20,40,60,80$ $\mu \mathrm{m})$ in the presence of Con A $(2 \mu \mathrm{g} / \mathrm{mL})$. After $72 \mathrm{~h}$, the CFSE-labeled splenocytes were analyzed by flow cytometry.

\section{Western blotting}

Proteins were extracted from the liver tissues and stored at $-80{ }^{\circ} \mathrm{C}$. For western blotting analysis, $60 \mu \mathrm{g}$ of total protein were loaded and separated with a $10 \%$ sodium dodecyl sulfate polyacrylamide gel electrophoresis (SDSPAGE) and transferred to polyvinylidene fluoride (PVDF) membranes. The membranes were blocked with $5 \%$ bovine serum albumin (BSA) for $1.5 \mathrm{~h}$ prior to being incubated overnight at $4{ }^{\circ} \mathrm{C}$ with antibodies against $\mathrm{Bax}(1: 2,000$, CST), Bcl-2 (1:1,000, Abcam), Nrf2 (1:500, Abcam), HO-1 (1:1,000, Abcam), NQO1 (1:2,000, Abcam), (p-Akt (1:1,000, CST), Akt (1:3,000, CST), p-GSK3 $\beta$ (1:500, CST), $\operatorname{GSK} 3 \beta(1: 2,000$, CST), $\beta$-actin (1:10,000, Abcam), and/or Lamin B1 (1:1,000, Abcam). Finally, the membranes were incubated with an HRP-conjugated goat anti-rabbit/mouse polyclonal secondary antibody (1:10,000, ASPEN) for $2 \mathrm{~h}$ at room temperature. Protein bands were visualized with a GeneGnome XRQ system (Syngene, UK).

\section{SYBR green real-time RT-PCR}

Total RNA from the liver tissues was extracted using the PrimeScript RT reagent kit (Takara, Japan), according to the manufacturer's instructions. Realtime quantitative PCR was performed using a $\mathrm{SYBR}^{\circledR}$ Premix Ex Taq II (Tli RNaseH Plus) (Takara, Japan). The primer sequences used were as follows: SOD2 (forward 5'-gTAgggCCTgTCCgATgATg-3' and reverse 5'-CgCTACTgAgAAAggTgCCA-3'); $\beta$-actin (forward 5'-GTGACGTTGACATCCGTAAAGA-3' and reverse 5'-GCCGGACTCATCGTACTCC-3'). Samples were analyzed using StepOne Software v2.3 (Thermo Fisher Scientific). For quantitative analysis, all samples were analyzed using the $\Delta \Delta \mathrm{CT}$ value method and normalized to $\beta$-actin.

\section{Histopathology}

Liver tissues were harvested $12 \mathrm{~h}$ after Con A injection, fixed in $4 \%$ paraformaldehyde, and embedded in paraffin. Sections with a thickness of $5 \mu \mathrm{m}$ were cut for $\mathrm{H} \& \mathrm{E}$ staining. Histopathological changes were observed under a light microscope and recorded. The severity of liver injury $12 \mathrm{~h}$ after Con A challenge was assessed in a blinded fashion according to Suzuki's histological criteria (25). Detailed information regarding Suzuki's histological criteria is shown in Table 1.

\section{Statistical analysis}

All data were analyzed using GraphPad Prism software and are presented as the mean \pm standard deviation (SD). All data were analyzed by one-way ANOVA (when three or more groups were compared), or by unpaired or two-tailed paired $t$-tests. Values of $\mathrm{P}<0.05$ were considered significant.

\section{Results}

\section{Daidzein pretreatment reduced Con A-induced acute liver injury and increased the survival rate}

To study the protective effect of daidzein against Con A-induced liver injury, we first administered a sublethal dose of Con A to mice via intravenous injection. Serum and liver tissue specimens were collected for analyses after $12 \mathrm{~h}$. Con A administration resulted in a 37.17- and 12.68-fold increase in ALT and AST, respectively $(\mathrm{P}<0.001)$. However, serum ALT $(\mathrm{P}<0.001)$ and AST $(\mathrm{P}<0.001)$ levels significantly decreased by $81.42 \%$ and $71.57 \%$, respectively, in the daidzein pretreatment group (Figure $1 A, B$ ). 
Table 1 Suzuki's histological criteria

\begin{tabular}{lccc}
\hline Grade & Congestion (\%) & Vacuolization (\%) & Necrosis (\%) \\
\hline 0 & None & None & Mone \\
1 & Minimal [10] & Minimal [10] & Mild [11-30] \\
2 & Mild [11-30] & Mild [11-30] & Moderate [31-60] \\
3 & Moderate [31-60] & Moderate [31-60] & Severe [>60] \\
4 & Severe [>60] & Severe [>60] & \\
\hline
\end{tabular}

Additionally, in the Con A group, the livers of mice were congested, swollen, and appeared dark red, with scattered blood spots on the surface. These morphological changes were significantly improved by daidzein pretreatment (Figure 1C). Subsequently, hematoxylin and eosin (H\&E) staining was performed on liver tissue, and histopathological changes in samples were observed under a microscope. After Con A injection, there was extensive congestion and edema in the hepatic sinus, accompanied by large areas of necrotic foci and a large amount of lymphocyte infiltration. Daidzein pretreatment significantly improved the pathological changes, which was consistent with the Suzuki score $(\mathrm{P}<0.01$, Figure $1 D, 1 E)$. To further examine the protective effect of daidzein against Con A-induced liver injury, we determined the survival rate. After administering a lethal dose of Con A $(25 \mathrm{mg} / \mathrm{kg}), 60 \%$ of the mice died within $20 \mathrm{~h}$. However, the survival rate of mice pretreated with daidzein was significantly better, with a $100 \%$ survival rate at $72 \mathrm{~h}($ Figure $1 F)$. Overall, these results indicate that daidzein pretreatment protected against Con A-induced liver injury.

Daidzein pretreatment reduced Con A-induced lymphocyte activation, the release of inflammatory cytokines, and hepatocyte apoptosis

Con A-induced liver injury is closely related to the activation of lymphocytes and the release of inflammatory cytokines. To investigate whether daidzein pretreatment can reduce Con A-induced inflammation, we analyzed the activation of intracellular lymphocytes in mouse liver and levels of various types of inflammatory cytokines, including TNF- $\alpha$, IL-2, IL-6, IL-10, IL-17, and IFN- $\gamma$, in mouse serum. As shown in Figure S1, Con A injection promoted high CD69 expression on the surface of $\mathrm{CD}^{+}$and $\mathrm{CD} 8^{+} \mathrm{T}$ cells, and a reduction in $\mathrm{T}$ cell activation was observed after daidzein pretreatment. Additionally, many inflammatory cytokines were present in the serum of the Con A-treated group, and the release of inflammatory cytokines was significantly reduced after daidzein pretreatment $(\mathrm{P}<0.01$ or $\mathrm{P}<0.001$, Figure $2 A-2 F)$. These results indicate that daidzein effectively inhibited the release of inflammatory cytokines induced by Con A, thereby playing a protective role in the liver.

Con A can induce hepatocyte apoptosis through multiple pathways, thereby causing liver injury. Liver tissue was subjected to TUNEL and cleaved caspase-3 staining to observe hepatocyte apoptosis. As shown in Figure 3, the areas of cleaved caspase-3-positive and TUNEL-positive cells in the Con A group increased 37.57- and 46.75fold, respectively, compared to those of the control group $(\mathrm{P}<0.001)$, while in the daidzein pretreatment group, cleaved caspase-3-positive and TUNEL-positive cells were reduced $74.14 \%$ and $64.49 \%$, respectively. $(\mathrm{P}<0.001$, Figure $3 A-3 D)$. The balance between the proapoptotic protein Bax and the antiapoptotic protein Bcl-2 determines whether cells survive or apoptosis occurs. Western blotting was used to analyze the Bax and Bcl-2 protein levels in liver tissue. Con A administration resulted in a 3.29-fold increase in Bax and a 79.07\% decrease in $\mathrm{Bcl}-2(\mathrm{P}<0.001)$. Daidzein pretreatment attenuated $48.21 \%$ of Bax and improved up to $28.15 \%$ of Con A-mediated depletion of Bcl-2 $(\mathrm{P}<0.05$ or $\mathrm{P}<0.01$, Figure $3 E-3 G)$. In addition, daidzein enhanced $33.44 \%$ of Con $\mathrm{A}$-induced reduction in Bcl-2/Bax $(\mathrm{P}<0.05$, Figure $3 H)$. The above results indicate that daidzein pretreatment reduced Con A-induced hepatocyte apoptosis.

\section{Daidzein pretreatment alleviated oxidative stress after Con A challenge}

Increasing evidence indicates that oxidative stress plays a crucial role in Con A-induced damage. ROS aggregation is the main cause of oxidative stress (26). The status of 


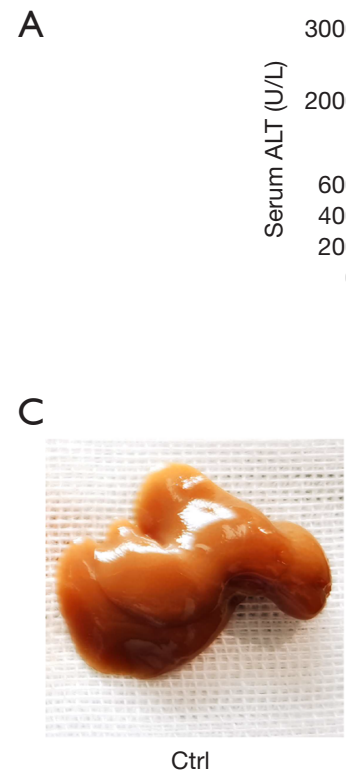

D

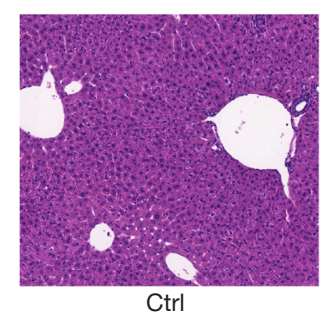

E

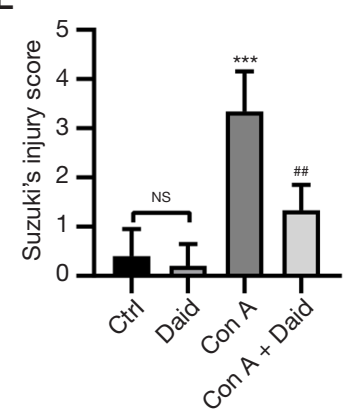

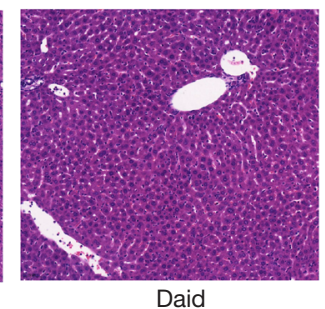
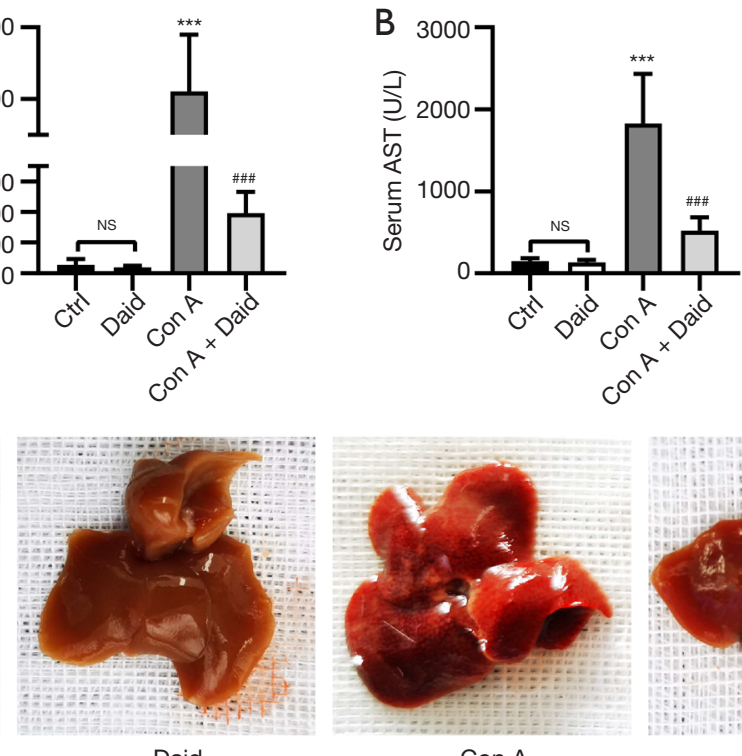

Daid

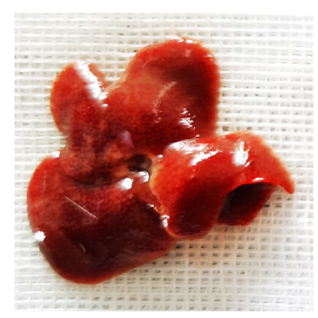

Con A

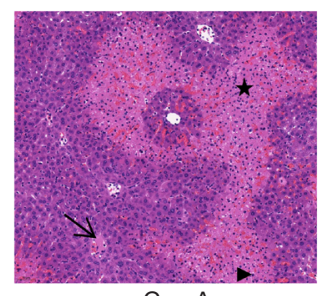

Con A

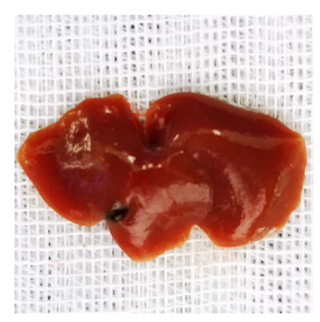

Con A + Daid

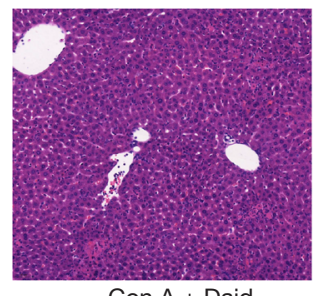

Con A + Daid

Figure 1 Daidzein alleviated Con A-induced liver injury. Mice were pretreated with daidzein (200 mg/kg, i.p.) for 3 days before the Con A injection. (A-E) Mice (n=6 per group) with or without daidzein pretreatment were injected with a sublethal dose of Con A (15 mg/kg, i.v.). $(\mathrm{A}, \mathrm{B})$ Serum ALT and AST levels in each group $12 \mathrm{~h}$ after Con A injection. (C) Morphological changes in the liver in each group. (D) Liver sections were stained with $\mathrm{H} \& \mathrm{E}$. The arrow indicates hepatic ecchymosis, the triangle indicates infiltrated leukocytes, and the star indicates an area of necrosis (original magnification 200x). (E) The degree of liver injury was evaluated with Suzuki's injury score. (F) Mice (n=10 per group) were given a lethal dose of Con A $(25 \mathrm{mg} / \mathrm{kg})$ with or without daidzein pretreatment, and the survival rate was recorded after $72 \mathrm{~h}$. These results were obtained from at least three independent experiments. Values are presented as the mean $\pm \mathrm{SD}$. ${ }^{* * *} \mathrm{P}<0.001$ vs. the control group; ${ }^{\# \#} \mathrm{P}<0.01$ and ${ }^{\# \# \#} \mathrm{P}<0.001$ vs. the Con A group. ALT, alanine aminotransferase; AST, aspartate aminotransferase; SD, standard deviation; NS, no significance; Ctrl, control; Daid, daidzein. 

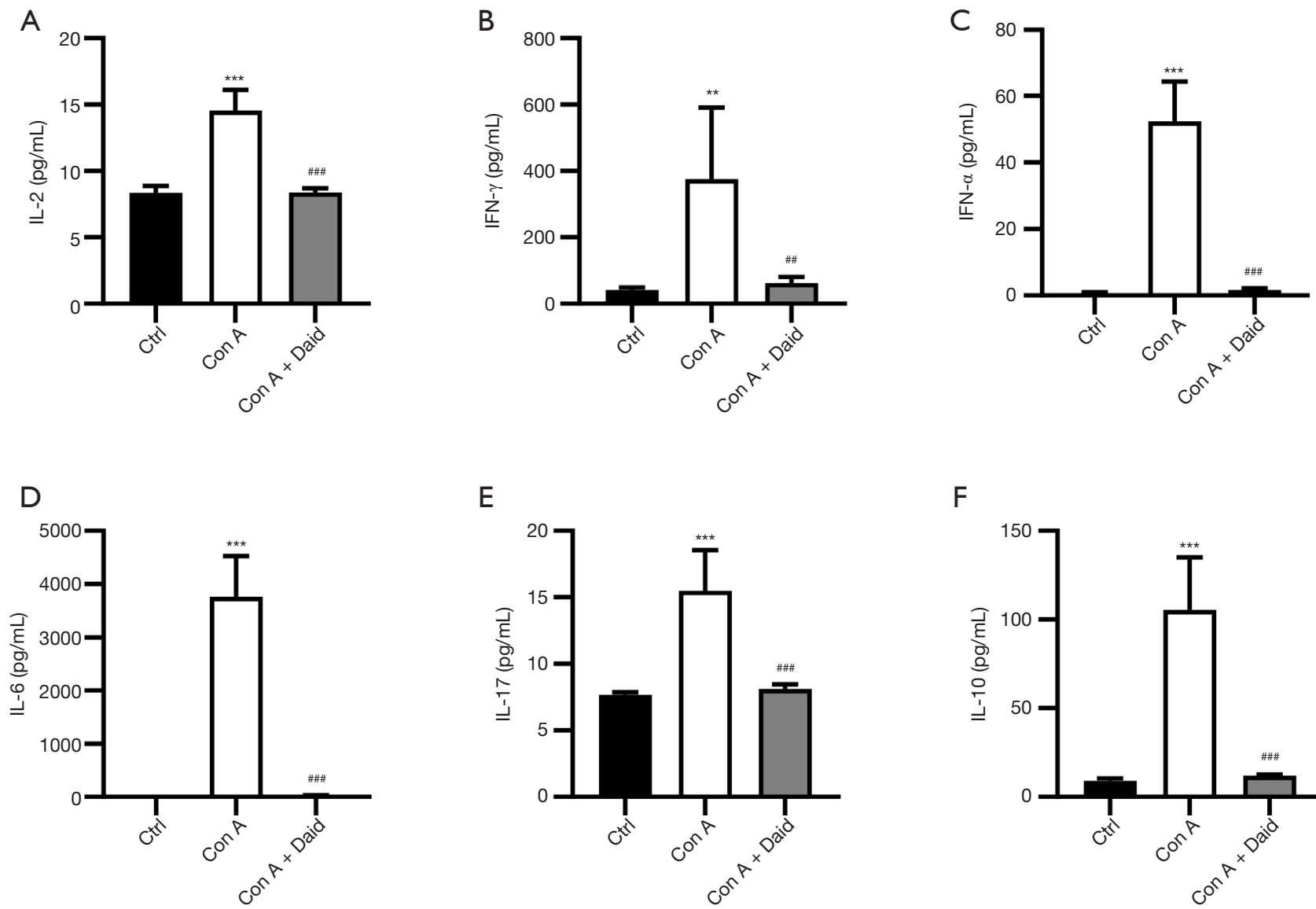

Figure 2 Effect of daidzein on inflammatory cytokine production in Con A-challenged mice. Serum samples were collected $12 \mathrm{~h}$ after Con A injection. Serum levels of IL-2 (A), IFN- $\gamma$ (B), TNF- $\alpha$ (C), IL-6 (D), IL-17 (E), and IL-10 (F) were quantified with CBA kits. Similar results were obtained from at least three independent experiments. Data are presented as the mean $\pm \mathrm{SD}$ ( $\mathrm{n}=6$ per group). ** $\mathrm{P}<0.01$ and *** $\mathrm{P}<0.001$ vs. the control group. ${ }^{\# \#} \mathrm{P}<0.01$ and ${ }^{\# \# \#} \mathrm{P}<0.001$ vs. the Con A group. CBA, cytometric bead array.

oxidative stress induced by Con A was evaluated by testing the level of ROS accumulation and antioxidant factors (SOD, SOD2, and GPX). The DHE fluorescence probe results indicated that the ROS fluorescence intensity in the Con A group was 3.86-fold higher than that in the control group $(\mathrm{P}<0.001)$, whereas it was significantly reduced by $37.20 \%$ after daidzein pretreatment $(\mathrm{P}<0.01$, Figure $4 A, 4 B)$. In addition, the activity of GPX $(\mathrm{P}<0.05)$, SOD $(\mathrm{P}<0.01)$, and SOD2 mRNA $(\mathrm{P}<0.001)$ expression in liver tissues induced by Con A were significantly reduced (31.01\%, 37.35\%, and $75.97 \%$, respectively). Treatment with daidzein significantly improved Con A-induced reduction in SOD, GPX, and SOD2 $(21.44 \%, 28.28 \%$, and $48.78 \%$, respectively) $(\mathrm{P}<0.05$ or $\mathrm{P}<0.01$, Figure $4 C-4 E)$. We also measured the oxidative factor $(\mathrm{MDA})$ in the liver. Con A-induced 2.15-fold increase in MDA $(\mathrm{P}<0.001)$ and daidzein pretreatment reduced $28.40 \%$ of $\mathrm{MDA}(\mathrm{P}<0.01$, Figure $4 F$ ) in Con A-induced liver injury. The above results verified the suppression role of daidzein in Con A-induced oxidative stress in the liver.

\section{Daidzein pretreatment ameliorated Con A-induced liver injury through Akt/GSK3B/Nrf2 signaling pathways}

To investigate the possible antioxidant mechanisms of daidzein in Con A-challenged mice, we next examined the activation of Nrf2 in liver tissues. As shown in Figure 5, compared with the control group, Nrf2 expression was reduced by $71.08 \%$ in Con $\mathrm{A}$-challenged mice $(\mathrm{P}<0.001)$. However, daidzein pretreatment improved up to $23.29 \%$ of Con A-induced decrease in Nrf2 nuclear translocation $(\mathrm{P}<0.05$, Figure $5 A, 5 B)$. As the downstream of the $\mathrm{Nrf} 2$ 
A

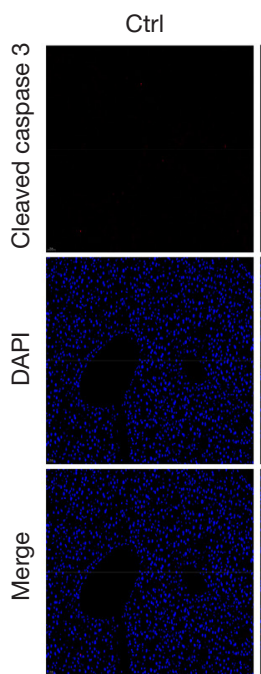

C

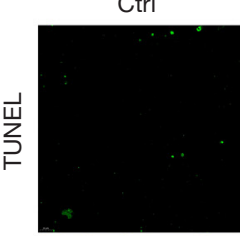

$\overline{\frac{1}{4}}$
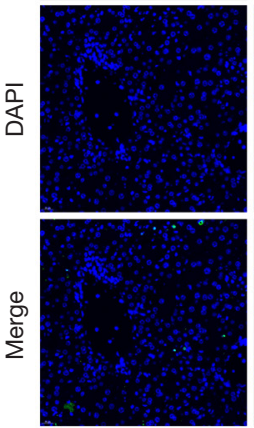

E
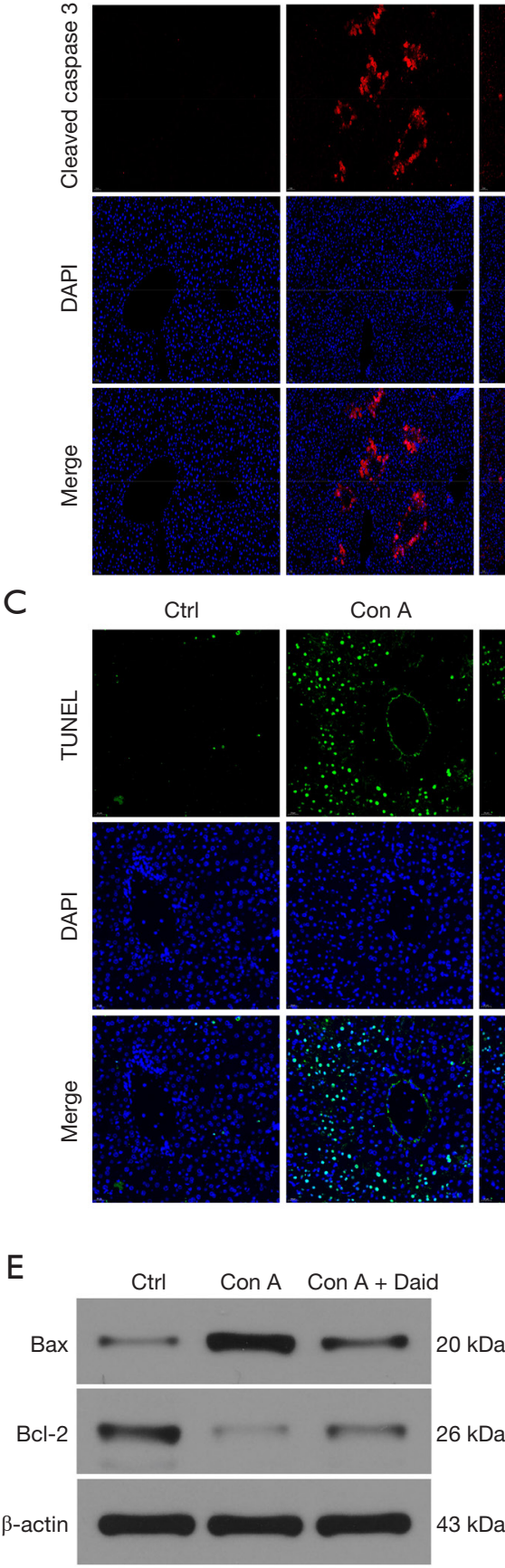

Con A
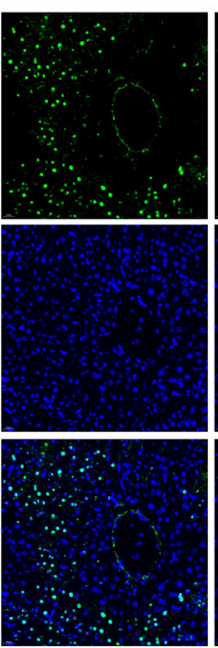

Con A + Daid
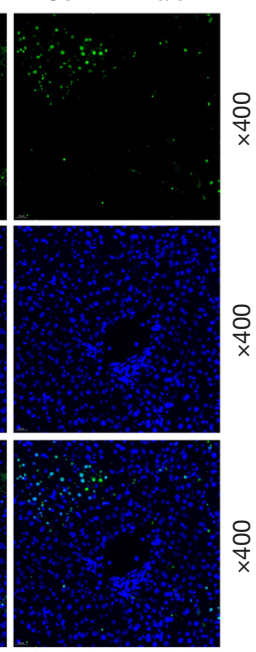

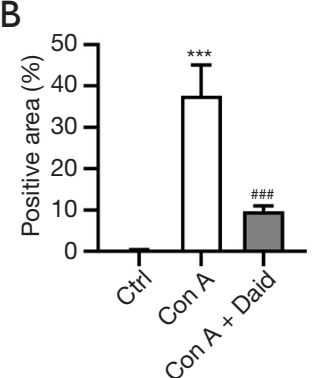

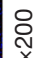

G

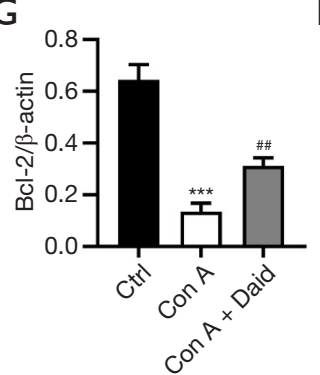

Con A + Daid

$\underset{+}{\stackrel{9}{x}}$

$\frac{1}{8}$

F
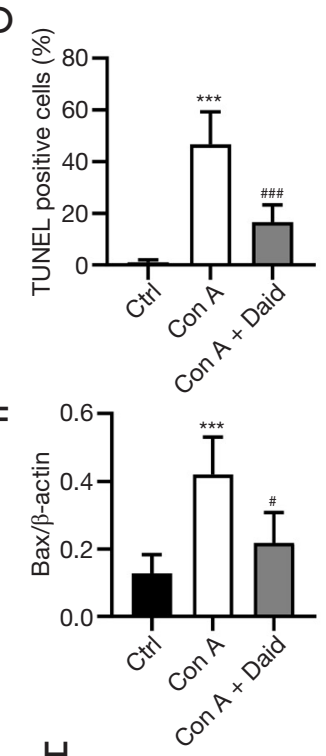

H

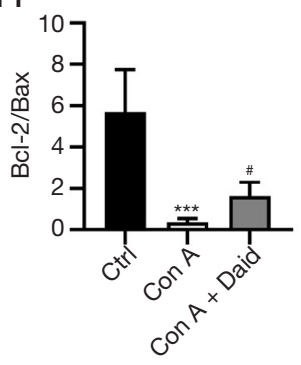

Figure 3 Effect of daidzein on hepatocyte apoptosis in Con A-induced hepatitis. Mice were intraperitoneally injected with daidzein $(200 \mathrm{mg} / \mathrm{kg})$ for 3 days before Con A (15 mg/kg, i.v.) administration, and liver samples were collected $12 \mathrm{~h}$ after Con A challenge. (A,B) Liver tissue sections were stained for cleaved caspase- 3 by immunofluorescence, and the positive area (percentage) was determined (original magnification 200x). (C,D) TUNEL staining was performed, and the percentage of positive cells was calculated (original magnification 400x). (E-H) The expression of Bax and Bcl-2 was determined by western blotting and densitometric analysis of the Bax/ $\beta$-actin, Bcl-2/ $\beta$-actin, and Bcl-2/Bax ratios are shown. The results represent the means from at least 3 independent experiments. Data are shown as the mean $\pm \mathrm{SD}$ ( $\mathrm{n}=4$ per group). ${ }^{* * *} \mathrm{P}<0.001$ vs. the control group; ${ }^{*} \mathrm{P}<0.05,{ }^{\# \#} \mathrm{P}<0.01$, and ${ }^{\# \# !} \mathrm{P}<0.001$ vs. the Con A group. TUNEL, terminal deoxynucleotidyl transferase (TdT) dUTP nick-end labeling. 
A

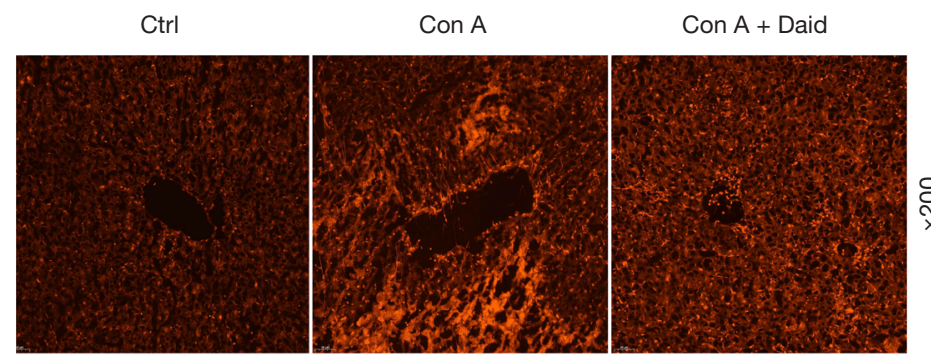

B

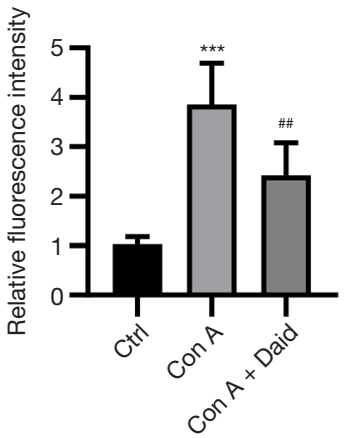

C

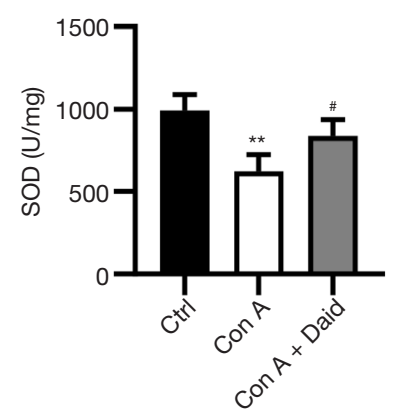

D

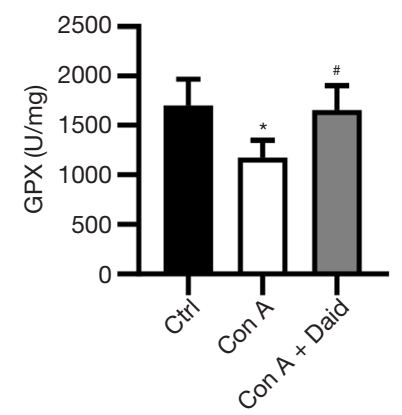

E

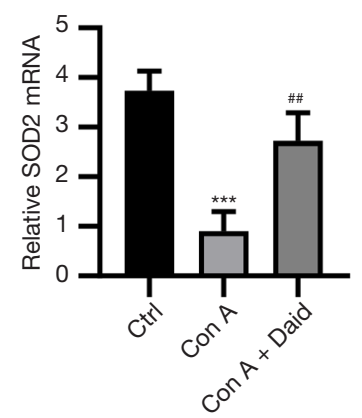

$\mathrm{F}$

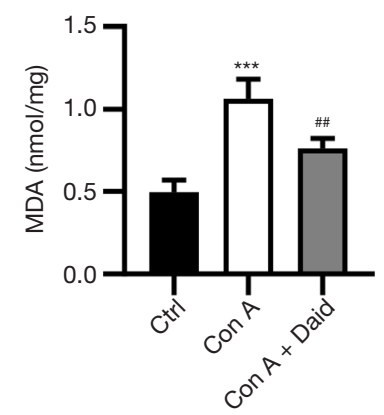

Figure 4 Effect of daidzein on Con A-induced oxidative stress in the liver. Mice were intraperitoneally pretreated with daidzein $(200 \mathrm{mg} / \mathrm{kg}$ ) for 3 days before Con A (15 mg/kg, i.v.) injection. (A) Immunofluorescence of DHE expression (original magnification 200×). (B) Relative fluorescence intensity in the liver. (C-F) levels of SOD, GPX activity, SOD2 mRNA and MDA activity in the liver. Similar results were obtained from at least three independent experiments. Values are shown as the mean $\pm \mathrm{SD}$ ( $\mathrm{n}=4$ per group). ${ }^{*} \mathrm{P}<0.05,{ }^{* *} \mathrm{P}<0.01$, and ${ }^{* * *} \mathrm{P}<0.001$ vs. the control group. ${ }^{\#} \mathrm{P}<0.05$ and ${ }^{\# \#} \mathrm{P}<0.01$ vs. the Con $\mathrm{A}$ group. $\mathrm{DHE}$, dihydroethidium.

signaling pathway, HO-1 and NQO1 were also analyzed by western blot. The expression of HO-1 $(\mathrm{P}<0.001)$ and NQO1 $(\mathrm{P}<0.001)$ induced by Con A were significantly reduced $(64.29 \%$ and $84.92 \%$, respectively), while HO-1 and NQO1 expression significantly increased after daidzein pretreatment (28.03\% and $27.84 \%$, respectively) $(\mathrm{P}<0.01$, Figure $5 A, C, D)$. These data indicate that daidzein might have protected against Con A-induced oxidative stress via the Nrf2 signaling pathway.

It has been reported that Cav-1 inhibition regulates the $\mathrm{PI} 3 \mathrm{~K} / \mathrm{Akt} / \mathrm{GSK} 3 \beta$ signaling pathway and that PI3K/Akt/ GSK3 $\beta$ pathway activation protects against Con A-induced liver injury (12). As the upstream of Nrf2, GSK3 $\beta$ positively regulates the degradation of $\mathrm{Nrf2}$, and the PI3K/Akt axis negatively regulates GSK3 $\beta$ via phosphorylation at Serine 9 (Ser 9) (27). Therefore, we theorized that daidzein regulated the expression of Nrf2 and HO-1 through the PI3K/Akt/
GSK3 $\beta$ signaling pathway. We detected the protein levels of p-Akt and p-GSK3 $\beta$ by western blotting. Compared with the control group, the protein expression of $\mathrm{p}-\mathrm{Akt}(\mathrm{P}<0.001)$ and $\mathrm{p}-\mathrm{GSK} 3 \beta(\mathrm{P}<0.001)$ in the Con A group significantly decreased $(75.58 \%$ and $74.50 \%$, respectively), while the expression of $\mathrm{p}-\mathrm{Akt}(\mathrm{P}<0.01)$ and $\mathrm{p}-\mathrm{GSK} 3 \beta(\mathrm{P}<0.01)$ after daidzein pretreatment significantly increased $(28.68 \%$ and $28.19 \%$, respectively) (Figure 5E-5G). In summary, daidzein prevented Con A-induced decrease in Nrf2 via the PI3K/ Akt/GSK3 $\beta$ pathway, thereby enhancing the antioxidative capability of liver tissues and protecting against Con A-induced liver injury.

\section{In vitro, daidzein pretreatment attenuated Con A-induced bepatocyte death in mice}

To further determine the protective mechanism of daidzein 


\section{Page 10 of 15}

A
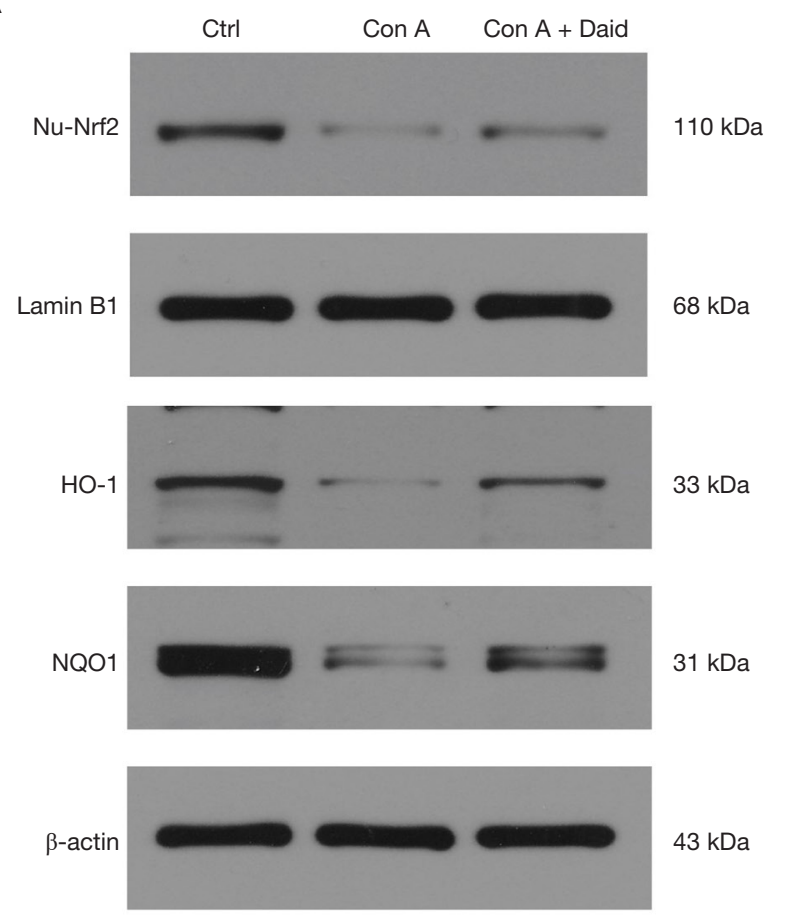

E
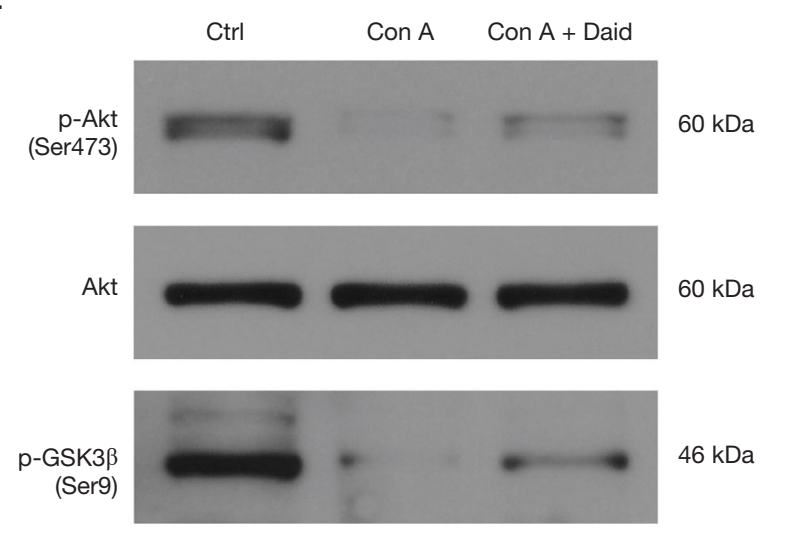

GSK3 $\beta$

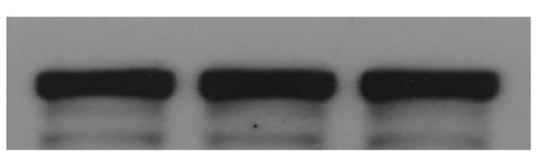

$46 \mathrm{kDa}$

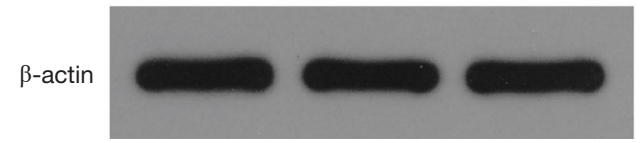

Li et al. Daidzein ameliorated Con A-induced liver injury in mice

B

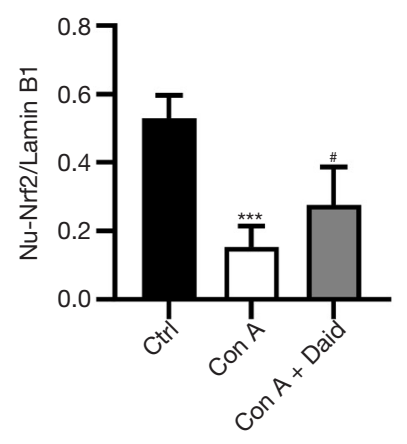

C

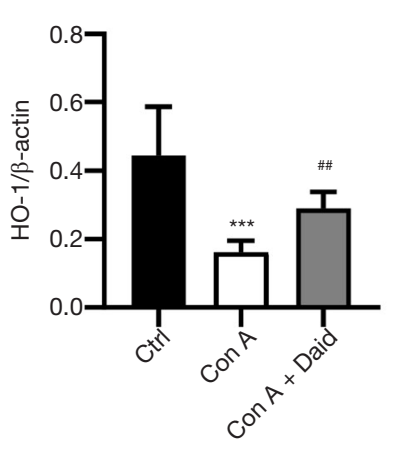

D

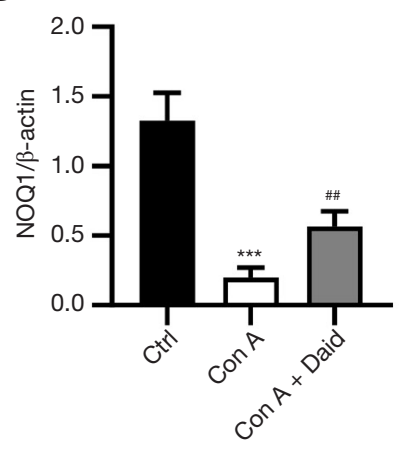

F

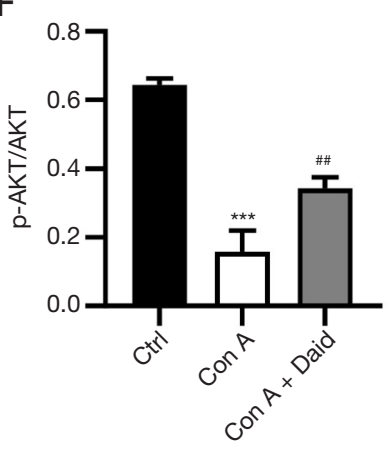

G

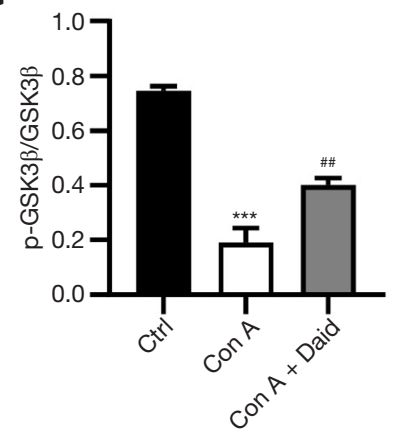

Figure 5 Effect of daidzein on Akt/GSK3ß/Nrf2 signaling in Con A-challenged mice. Mice were sacrificed, and liver tissues were harvested $12 \mathrm{~h}$ after Con A injection. (A-D) Western blot analysis showing nuclear Nrf2, HO-1, and NQO1 expression in the liver and (E-G) western blot analysis showing p-Akt and p-GSK3 $\beta$ expression in the liver. All the results were obtained from at least three independent experiments. Data are expressed as the mean $\pm \mathrm{SD}$ ( $\mathrm{n}=4$ per group). ${ }^{* * *} \mathrm{P}<0.001$ vs. the control group. ${ }^{\#} \mathrm{P}<0.05$ and ${ }^{\# \#} \mathrm{P}<0.01$ vs. the Con $\mathrm{A}$ group. 
against Con A-induced liver injury, we conducted in vitro experiments to validate the effect of daidzein on Con A-induced hepatocyte death and lymphocyte activation in mice. We first treated AML-12 cells with different concentrations of daidzein for $6 \mathrm{~h}$, followed by treatment with Con $\mathrm{A}$ at a concentration of $10 \mu \mathrm{g} / \mathrm{mL}$ for $12 \mathrm{~h}$. The viability and apoptosis of AML-12 cells after $12 \mathrm{~h}$ of Con A treatment were determined using a CCK-8 assay and Annexin V-FITC/PI apoptosis detection kit. The results showed that compared with the control group cells, Con A-treated cells exhibited a significant reduction in cell viability $(41.68 \%, \mathrm{P}<0.001)$. However, after pretreatment with different concentrations of daidzein, cell viability significantly improved $12.24 \%, 25.24 \%, 29.68 \%$, and $20.14 \%$, respectively, $\mathrm{P}<0.05, \mathrm{P}<0.01$ or $\mathrm{P}<0.001)$. Moreover, the protective effect of daidzein against Con A-induced AML-12 cell cytotoxicity was partly diminished by a PI3K/Akt signaling pathway inhibitor (LY294002) $(\mathrm{P}<0.05$, Figure $6 A, 6 B)$. We further verified the protective effect of daidzein against Con A-induced AML-12 cell death by flow cytometry, and the results were consistent with the CCK-8 assay (Figure 6C,6D). These results indicate that the protective effect of daidzein against Con A-induced AML12 cell death occurred via the PI3K/Akt/GSK3 $\beta$ signaling pathway.

Next, we observed the effect of daidzein pretreatment on Con A-induced spleen lymphocyte proliferation and cytokine secretion in mice. Con A stimulation significantly induced mouse lymphocyte proliferation, accompanied by the secretion of a large number of cytokines, while only a slight decrease in cytokine secretion was observed in the daidzein pretreatment group with the highest concentration of daidzein (Figure S2). The above in vitro results demonstrate that daidzein played a protective role in the liver mainly through the protection of hepatocytes rather than the inhibition of lymphocyte activation.

\section{Discussion}

AIH is a chronic inflammatory disease with high levels of morbidity and mortality. The pooled worldwide annual incidence and prevalence of AIH were 1.37 and 17.44 per 100,000 persons, respectively (2). Currently, there are no effective treatments for AIH; therefore, it poses a serious threat to human life and health, causing a large global burden. In our study, we found that daidzein significantly reduced Con A-induced liver injury. After Con A injection, serum ALT, AST, and inflammatory cytokines significantly increased, while daidzein pretreatment significantly reduced serum levels of ALT, AST, and inflammatory cytokines, while oxidative stress and hepatocyte apoptosis in the liver were also alleviated. We demonstrated for the first time that daidzein pretreatment had protective effects against Con A-induced murine AIH, which might provide new therapeutic strategies for $\mathrm{AIH}$ treatment in the future.

Con $\mathrm{A}$ is a potent stimulator that can trigger an in vitro immune response (28). In addition, Con A causes direct toxicity to hepatocytes due to the excessive activation of membrane receptors and subsequent cytoskeleton disorders, which are related to its strong affinity for the hepatocyte cell membrane (11). In in vitro studies, we found that daidzein pretreatment had very little effect on Con A-induced lymphocyte proliferation and the release of inflammatory cytokines in mice. In addition, the treatment of hepatocytes with Con A caused an inflammatory microenvironment. At the same time, daidzein pretreatment significantly inhibited the direct induction of hepatocyte death by Con A. These results indicate that the effect of daidzein on $\mathrm{T}$ cells was relatively small and that the protective effect of daidzein in the liver was mainly achieved through the protection of the liver parenchymal cells. Our in vitro experiments provide clear evidence for the direct protective effect of daidzein in Con A-induced liver injury.

In recent years, it has been generally believed that the activation of the Nrf2 signaling pathway protects against oxidative stress-induced injury in cells $(29,30)$. As a transcription factor, $\mathrm{Nrf2}$ regulates the basic and inducible transcription of genes that encode molecules that protect against various oxidative stresses and produce GPX to regulate the cellular antioxidant system $(31,32)$. In response to a series of oxidative and electrophilic stimuli, $\mathrm{Nrf2}$ is activated. It mediates the production of a series of cytoprotective proteins, including some stage II enzymes such as $\mathrm{SOD}, \mathrm{NAD}(\mathrm{P}) \mathrm{H}$ : quinone oxidoreductase 1 (NQO-1), and catalase (CAT), as well as antioxidative proteins such as $\mathrm{HO}-1$. Nrf2 protects against oxidative stress through these antioxidant response elements (33). This study found that daidzein reversed Con A-induced reduction in Nrf2, HO-1, and NOQ1 expression, thereby reducing ROS accumulation, increasing SOD and GPX activity, and SOD2 mRNA levels in the liver. These results indicate that daidzein resisted the oxidative stress response induced by Con A stimulation through the Nrf2 pathway, thereby exerting protective effects against liver injury.

The mechanism of Con A-induced acute hepatitis involves many signaling pathways. Recent studies have 
A

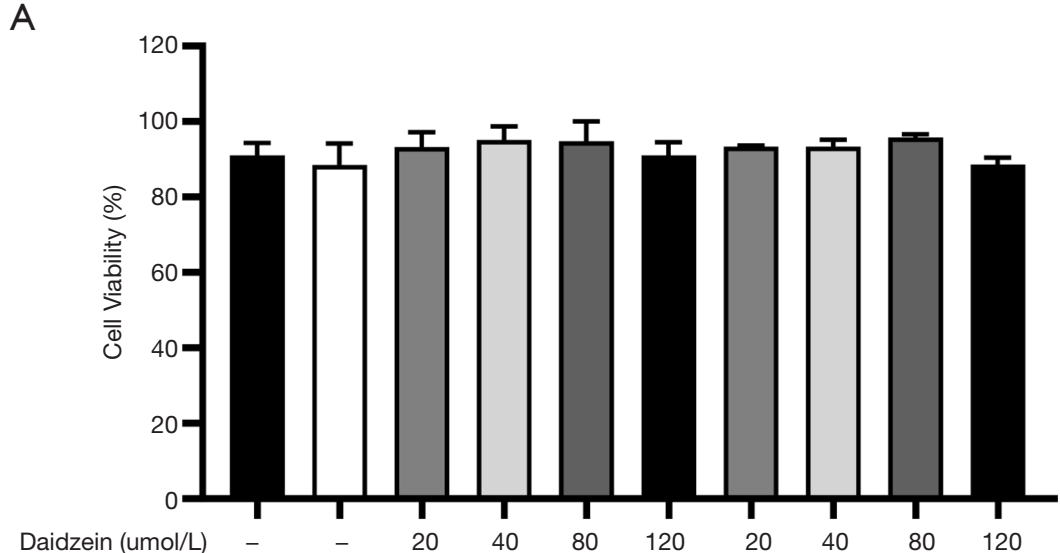

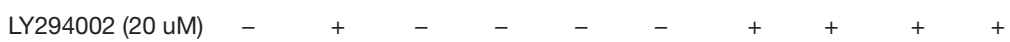

B

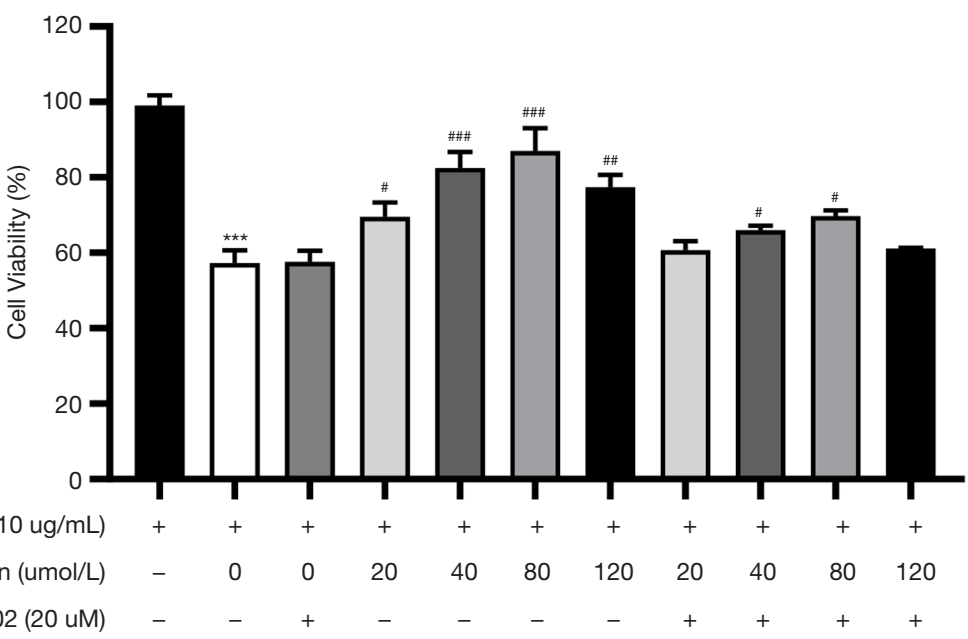

C

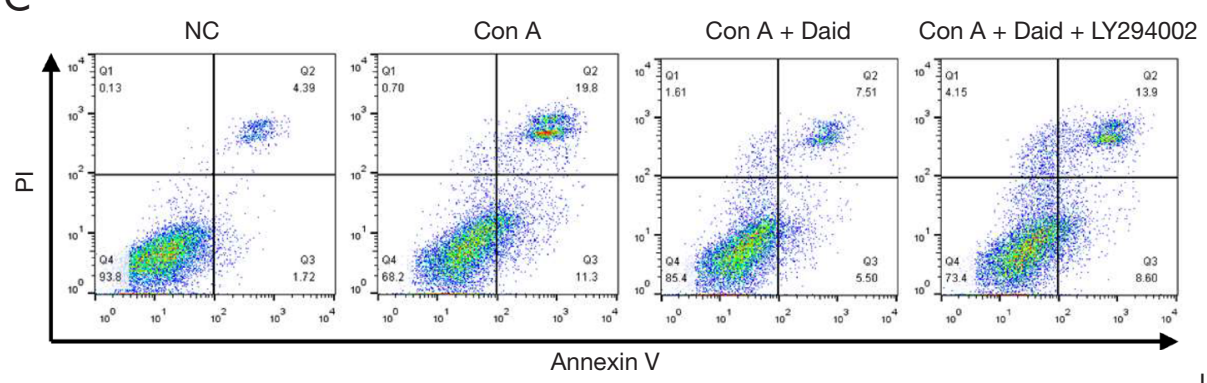

D

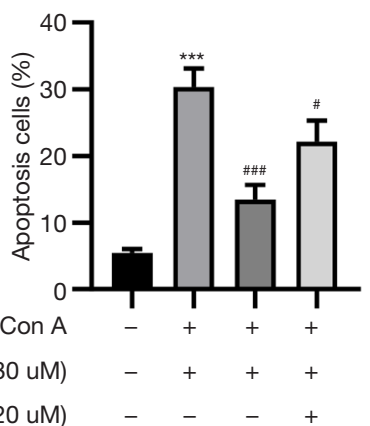

Figure 6 Daidzein protected AML-12 hepatocytes from Con A-induced apoptosis, and Akt phosphorylation was involved in the daidzeinmediated protective effects. AML-12 cells were seeded in 96-well plates, the cells were pretreated with daidzein $(20,40,80,120 \mu \mathrm{m})$ for $6 \mathrm{~h}$ and treated with Con A $(10 \mu \mathrm{g} / \mathrm{mL})$ for $12 \mathrm{~h}$. The group without daidzein pretreatment or Con A stimulation served as the control group. (A) The effect of daidzein and LY294002 on AML-12 cell viability under normal conditions. (B) AML-12 cells were pretreated with daidzein with or without LY294002 (20 $\mu \mathrm{m})$ and then treated with Con A for 12 h. A CCK-8 assay assessed cell viability. (C,D) The Annexin V and PI dual-labeling technique was used to analyze the effect of daidzein $(80 \mu \mathrm{m})$ on Con A-induced AML-12 cell apoptosis. These results were obtained from at least three independent experiments. All values are expressed as the mean $\pm \mathrm{SD}$ ( $\mathrm{n}=6$ per group). ${ }^{* * *} \mathrm{P}<0.001 v$ s. the control group. ${ }^{\#} \mathrm{P}<0.05,{ }^{\# \#} \mathrm{P}<0.01$ and $^{\# \# \#} \mathrm{P}<0.001$ vs. the Con $\mathrm{A}$ group. 


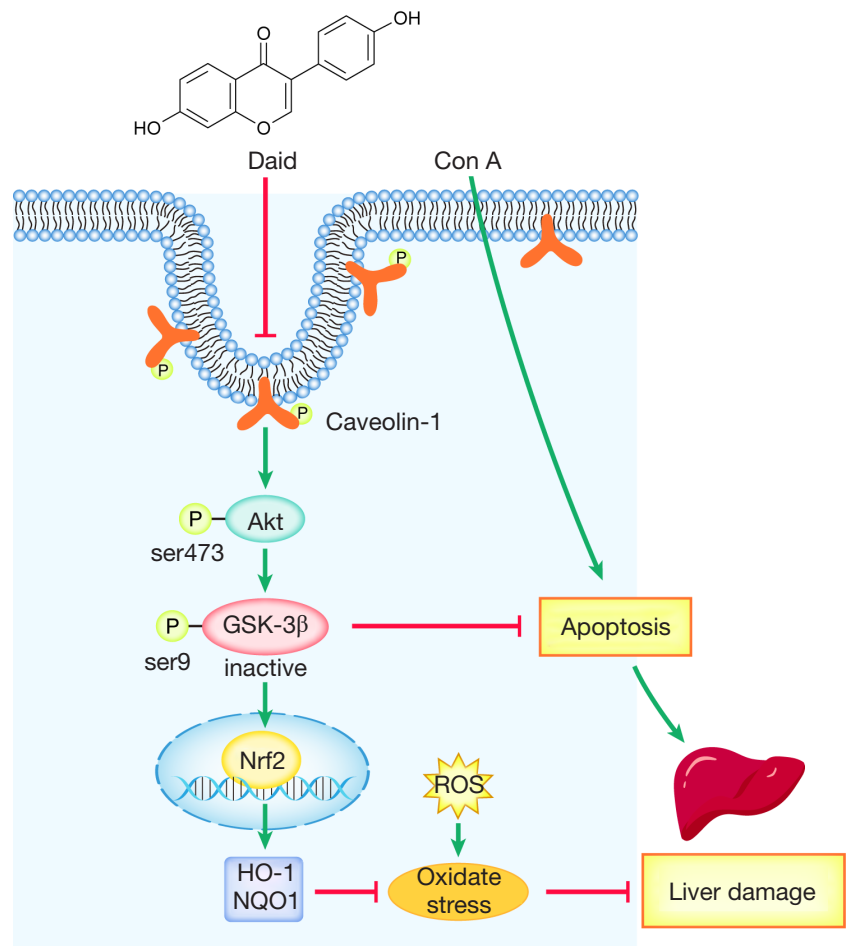

Figure 7 Mechanism of the protective effect of daidzein in Con A-induced liver injury. Daidzein regulates Nrf2 signaling and Bax and Bcl-2 expression via the PI3K/Akt/GSK-3 $\beta$ pathway, thereby reducing the oxidative stress response and hepatocyte apoptosis, which eventually alleviates liver damage in Con A-induced hepatitis.

shown that p-Akt activation significantly reduces Con A-induced liver injury (34-36). The PI3K/Akt signaling pathway is an important pathway that regulates cell survival, proliferation, and apoptosis (37). As the upstream of Nrf2, GSK3 $\beta$ positively regulates the degradation of $\mathrm{Nrf2}$, and the PI3K/Akt axis negatively regulates GSK3 $\beta$ via phosphorylation at Serine 9 (Ser 9) (27). Therefore, we assumed that daidzein resisted the oxidative stress response and hepatocyte apoptosis via the PI3K/Akt signaling pathway. Our study showed that after the Con A injection, the protein expression of p-Akt and p-GSK3 $\beta$ decreased in the liver. As a specific inhibitor of Cav-1, daidzein can regulate the PI3K/Akt signaling pathway and increase Bcl-2 expression while reducing Bax expression by preventing Con A-induced decrease in p-Akt and p-GSK3 $\beta$. Ultimately, cleaved caspase- 3 is reduced, thereby reducing hepatocyte apoptosis. To confirm that daidzein directly protects hepatocytes through the PI3K/Akt signaling pathway, a specific PI3K inhibitor (LY294002) was used to inhibit PI3K/Akt signaling pathway activation. PI3K inhibitors partly diminished the protective effect of daidzein in liver cells. These results clearly demonstrate that the protective effect of daidzein against Con A-induced liver injury was achieved by regulating the PI3K/Akt signaling pathway.

In summary, our study investigated the protective effect of daidzein pretreatment in a Con A-induced hepatitis model. Daidzein reduced the oxidative stress response and hepatocyte apoptosis through the PI3K/Akt/GSK3 $\beta$ signaling pathway (Figure 7). This study provides a new direction for the clinical treatment of AIH.

\section{Acknowledgments}

Funding: This work was supported by the National Natural Science Foundation of China (81873624).

\section{Footnote}

Reporting Checklist: The authors have completed the ARRIVE reporting checklist. Available at https://dx.doi. org/10.21037/atm-21-378

Data Sharing Statement: Available at https://dx.doi. org/10.21037/atm-21-378

Conflicts of Interest: All authors have completed the ICMJE uniform disclosure form (available at https://dx.doi. org/10.21037/atm-21-378). The authors have no conflicts of interest to declare.

Ethical Statement: The authors are accountable for all aspects of the work in ensuring that questions related to the accuracy or integrity of any part of the work are appropriately investigated and resolved. All procedures involving animals were performed and monitored in compliance with the guidelines of Tongji Animal Use Regulations and approved by the Institutional Animal Care and Use Committee (IACUC) of Tongji Medical College (number TJH-201902003).

Open Access Statement: This is an Open Access article distributed in accordance with the Creative Commons Attribution-NonCommercial-NoDerivs 4.0 International License (CC BY-NC-ND 4.0), which permits the noncommercial replication and distribution of the article with the strict proviso that no changes or edits are made and the 


\section{Page 14 of 15}

original work is properly cited (including links to both the formal publication through the relevant DOI and the license). See: https://creativecommons.org/licenses/by-nc-nd/4.0/.

\section{References}

1. Manns MP, Lohse AW, Vergani D. Autoimmune hepatitis-Update 2015. Journal of hepatology 2015;62:S100-S111.

2. Lv T, Li M, Zeng N, et al. Systematic review and metaanalysis on the incidence and prevalence of autoimmune hepatitis in Asian, European, and American population. J Gastroenterol Hepatol 2019;34:1676-84.

3. Liberal R, Longhi MS, Mieli-Vergani G, et al. Pathogenesis of autoimmune hepatitis. Best Pract Res Clin Gastroenterol 2011;25:653-64.

4. Ichiki Y, Aoki CA, Bowlus CL, et al. T cell immunity in autoimmune hepatitis. Autoimmun Rev 2005;4:315-21.

5. Liwinski T, Schramm C. Autoimmune hepatitis - update on clinical management in 2017. Clin Res Hepatol Gastroenterol 2017;41:617-25.

6. Christen U. Animal models of autoimmune hepatitis. Biochim Biophys Acta Mol Basis Dis 2019;1865:970-81.

7. Wang HX, Liu M, Weng SY, et al. Immune mechanisms of Concanavalin A model of autoimmune hepatitis. World J Gastroenterol 2012;18:119-25.

8. Tiegs G. Cellular and cytokine-mediated mechanisms of inflammation and its modulation in immune-mediated liver injury. Z Gastroenterol 2007;45:63-70.

9. Tan X, Sun L, Li Q, et al. Secoemestrin C inhibits activation of NKT/conventional T cells and protects against concanavalin A-induced autoimmune hepatitis in mice. Am J Transl Res 2020;12:3389-401.

10. Watanabe $Y$, Morita $M$, Akaike T. Concanavalin A induces perforin-mediated but not Fas-mediated hepatic injury. Hepatology 1996;24:702-10.

11. Leist $M$, Wendel A. A novel mechanism of murine hepatocyte death inducible by concanavalin A.J Hepatol 1996;25:948-59.

12. Xu S, Wu L, Zhang Q, et al. Pretreatment with propylene glycol alginate sodium sulfate ameliorated concanavalin A-induced liver injury by regulating the PI3K/Akt pathway in mice. Life sciences 2017;185:103-13.

13. Gao Y, Wáng Y, Wāng Y, et al. Protective Function of Novel Fungal Immunomodulatory Proteins Fip-lti1 and Fip-lti2 from Lentinus tigrinus in Concanavalin A-Induced Liver Oxidative Injury. Oxid Med Cell Longev 2019;2019:3139689.

14. Zaheer K, Humayoun Akhtar M. An updated review of
Li et al. Daidzein ameliorated Con A-induced liver injury in mice

dietary isoflavones: Nutrition, processing, bioavailability and impacts on human health. Crit Rev Food Sci Nutr 2017;57:1280-93.

15. Sakamoto Y, Kanatsu J, Toh M, et al. The Dietary Isoflavone Daidzein Reduces Expression of ProInflammatory Genes through PPAR $\alpha / \gamma$ and JNK Pathways in Adipocyte and Macrophage Co-Cultures. PLoS One 2016;11:e0149676.

16. Choi EJ, Kim GH. Hepatoprotective effects of daidzein against 7,12-dimetylbenz[a]anthracene-induced oxidative stress in mice. Int J Mol Med 2009;23:659-64.

17. Park HJ, Jeon YK, You DH, et al. Daidzein causes cytochrome c-mediated apoptosis via the Bcl-2 family in human hepatic cancer cells. Food Chem Toxicol 2013;60:542-9.

18. Choi EJ, Kim GH. Daidzein causes cell cycle arrest at the G1 and G2/M phases in human breast cancer MCF-7 and MDA-MB-453 cells. Phytomedicine 2008;15:683-90.

19. Jia GL, Huang Q, Cao YN, et al. Cav-1 participates in the development of diabetic neuropathy pain through the TLR4 signaling pathway. J Cell Physiol 2020;235:2060-70.

20. Jia S, Li B, Huang J, et al. Regulation of Glycogen Content in Astrocytes via Cav-1/PTEN/AKT/GSK-3 $\beta$ Pathway by Three Anti-bipolar Drugs. Neurochem Res 2018;43:1692-701.

21. Jung JH, Kim HS. The inhibitory effect of black soybean on hepatic cholesterol accumulation in high cholesterol and high fat diet-induced non-alcoholic fatty liver disease. Food Chem Toxicol 2013;60:404-12.

22. Kim SH, Heo JH, Kim YS, et al. Protective effect of daidzin against $\mathrm{D}$-galactosamine and lipopolysaccharideinduced hepatic failure in mice. Phytother Res 2009;23:701-6.

23. Watarai H, Nakagawa R, Omori-Miyake M, et al. Methods for detection, isolation and culture of mouse and human invariant NKT cells. Nat Protoc 2008;3:70-8.

24. Liu L, Kou P, Zeng Q, et al. CD4+ T Lymphocytes, especially Th2 cells, contribute to the progress of renal fibrosis. Am J Nephrol 2012;36:386-96.

25. Ge M, Yao W, Yuan D, et al. Brg1-mediated Nrf2/HO-1 pathway activation alleviates hepatic ischemia-reperfusion injury. Cell Death Dis 2017;8:e2841.

26. Jaeschke H, McGill MR, Ramachandran A. Oxidant stress, mitochondria, and cell death mechanisms in druginduced liver injury: lessons learned from acetaminophen hepatotoxicity. Drug Metab Rev 2012;44:88-106.

27. Wang L, Zhang S, Cheng H, et al. Nrf2-mediated liver 
protection by esculentoside A against acetaminophen toxicity through the AMPK/Akt/GSK3 $\beta$ pathway. Free Radic Biol Med 2016;101:401-12.

28. Taniguchi K, Kawano YI, Toshitani A, et al. Antimetastatic effect by in vivo administration of concanavalin A through augmentation of T-derived activated killer activity: efficacy to B16 melanoma expressed MHC antigen. Cell Immunol 1989;120:460-9.

29. Zhang J, Tong W, Sun H, et al. Nrf2-mediated neuroprotection by MANF against 6-OHDA-induced cell damage via PI3K/AKT/GSK3 $\beta$ pathway. Exp Gerontol 2017;100:77-86.

30. Zhang J, Ding C, Zhang S, et al. Neuroprotective effects of astaxanthin against oxygen and glucose deprivation damage via the PI3K/Akt/GSK3 $\beta / \mathrm{Nrf} 2$ signalling pathway in vitro. J Cell Mol Med 2020;24:8977-85.

31. Ha KN, Chen Y, Cai J, et al. Increased glutathione synthesis through an ARE-Nrf2-dependent pathway by zinc in the RPE: implication for protection against oxidative stress. Invest Ophthalmol Vis Sci 2006;47:2709-15.

Cite this article as: $\mathrm{Li} \mathrm{SL}, \mathrm{Cao} \mathrm{R}, \mathrm{Hu} \mathrm{XF}$, Xiong P, Zhao GY, Xie YN, Wang ZM, Li YK, Yang B, Yang J. Daidzein ameliorated concanavalin A-induced liver injury through the Akt/GSK-3ß/Nrf2 pathway in mice. Ann Transl Med 2021;9(15):1228. doi: 10.21037/atm-21-378
32. Gorrini C, Harris IS, Mak TW. Modulation of oxidative stress as an anticancer strategy. Nat Rev Drug Discov 2013;12:931-47.

33. Zhao Y, Song W, Wang Z, et al. Resveratrol attenuates testicular apoptosis in type 1 diabetic mice: Role of Aktmediated Nrf2 activation and p62-dependent Keap1 degradation. Redox Biol 2018;14:609-17.

34. Cheng P, Chen K, Xia Y, et al. Hydrogen sulfide, a potential novel drug, attenuates concanavalin A-induced hepatitis. Drug Des Devel Ther 2014;8:1277-86.

35. Wang C, Xia Y, Zheng Y, et al. Protective effects of $\mathrm{N}$-acetylcysteine in concanavalin A-induced hepatitis in mice. Mediators Inflamm 2015;2015:189785.

36. Mao Y, Wang J, Yu F, et al. Ghrelin reduces liver impairment in a model of concanavalin A-induced acute hepatitis in mice. Drug Des Devel Ther 2015;9:5385-96.

37. Yu JS, Cui W. Proliferation, survival and metabolism: the role of $\mathrm{PI} 3 \mathrm{~K} / \mathrm{AKT} / \mathrm{m}$ TOR signalling in pluripotency and cell fate determination. Development 2016;143:3050-60.

(English Language Editors: A. Muijlwijk and J. Chapnick) 
A

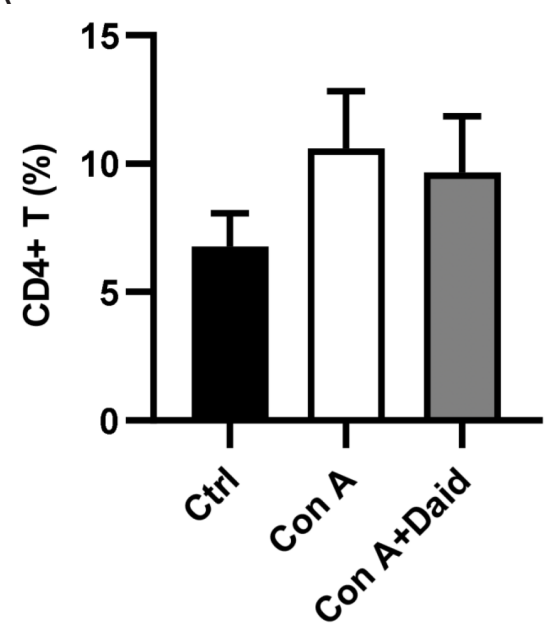

C

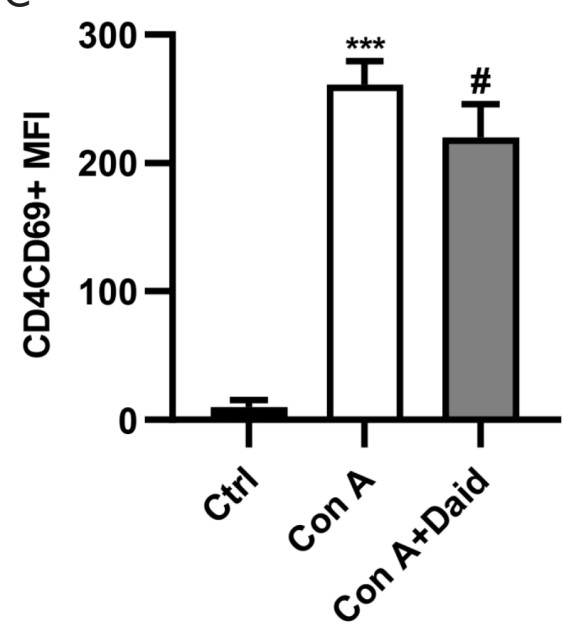

B

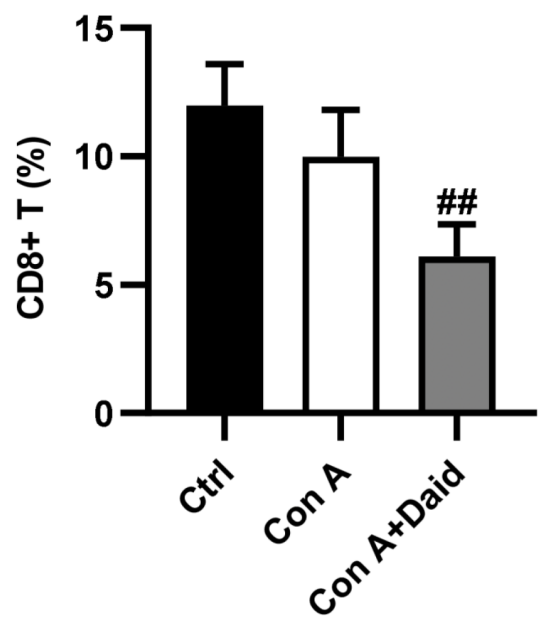

D

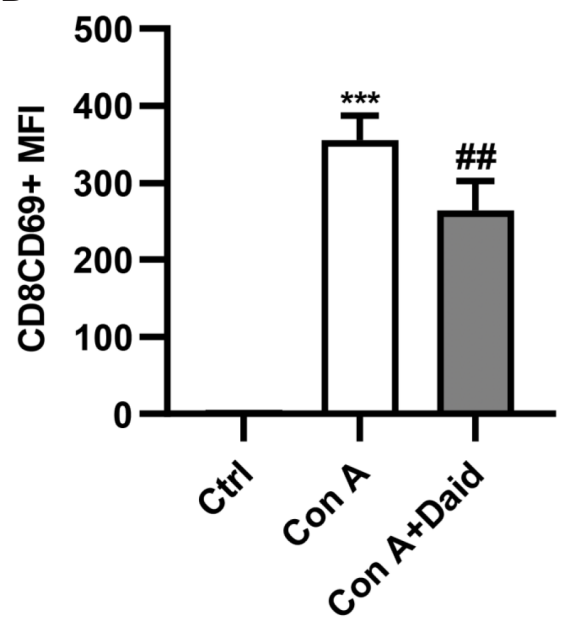

Figure S1 Effect of daidzein on T cell activation in Con A-induced hepatitis. Liver tissues were harvested $12 \mathrm{~h}$ after Con A injection, and liver MNCs were collected. The cells were stained with antibodies against CD3, CD4, CD8 and CD69 and then analyzed by flow cytometry. $(\mathrm{A}, \mathrm{B})$ The proportions of $\mathrm{CD} 4+$ and $\mathrm{CD} 8+\mathrm{T}$ cells in the $\mathrm{CD} 3+$ subset in the liver. $(\mathrm{C}, \mathrm{D})$ The mean fluorescence intensity (MFI) of CD4+CD69+ and CD8+CD69+ on every subset of the NC, Con A-treated, and Con A + Daid-treated groups. All the results were obtained from at least three independent experiments. Data are shown as the mean $\pm \mathrm{SD}$ ( $\mathrm{n}=6$ per group). ${ }^{* t *} \mathrm{P}<0.001$ vs. the Control group. ${ }^{\#} \mathrm{P}<0.05$ and ${ }^{\# !} \mathrm{P}<0.01$ vs. the Con $\mathrm{A}$ group. $\mathrm{SD}$, standard deviation. 

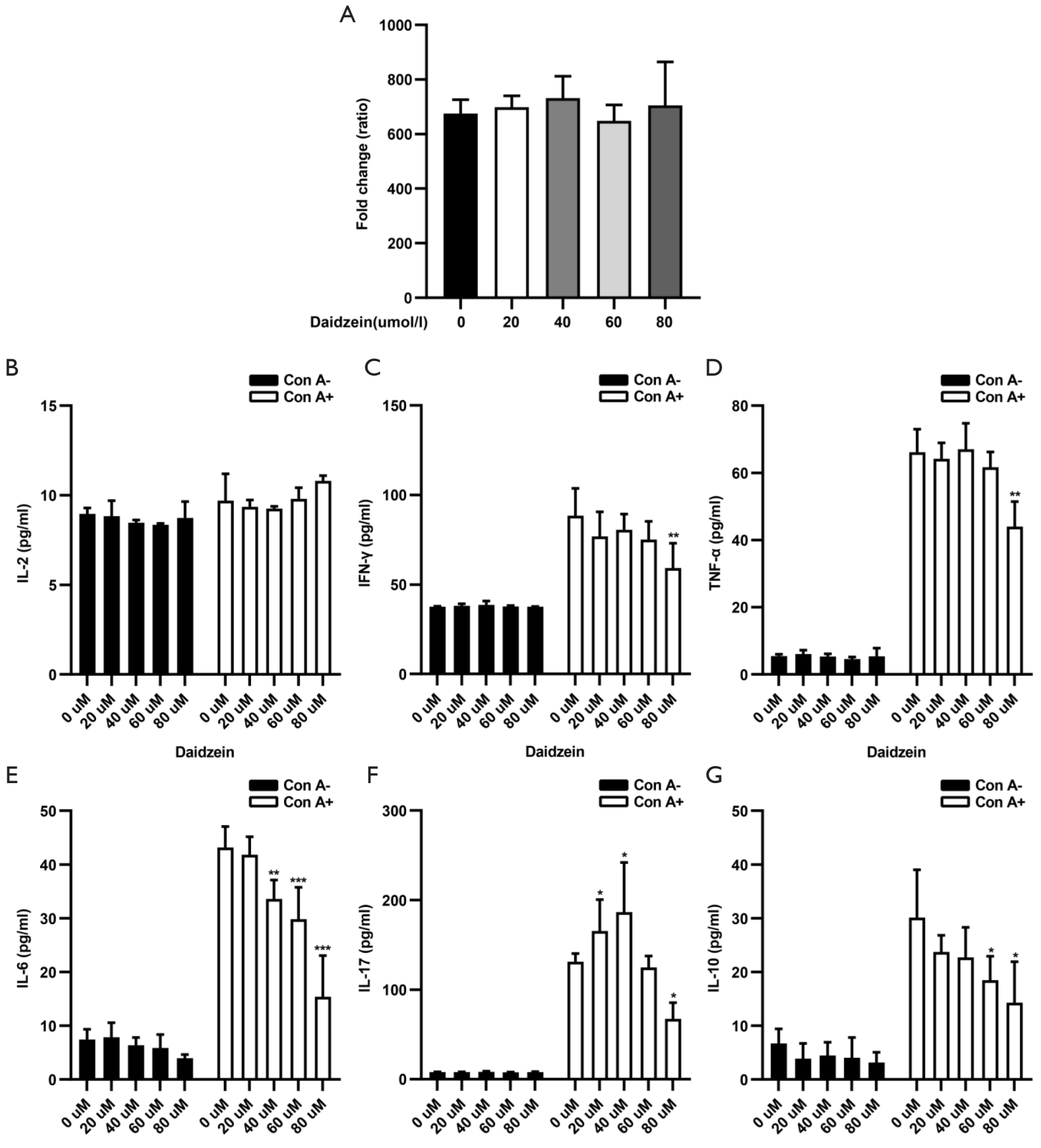

Figure S2 Effect of daidzein on the proliferation and inflammatory cytokine secretion of Con A-stimulated splenocytes. Splenocytes from B6 mice were stimulated with $2 \mu \mathrm{g} / \mathrm{mL}$ Con A in the presence or absence of different concentrations of daidzein. After $72 \mathrm{~h}$ of culture, splenocyte proliferation was determined by a CFSE dilution assay. Cytokine concentrations in culture supernatants were quantified by CBA kits. (A) The proliferation of splenocytes was assessed by a CFSE dilution assay. (B-G) The levels of IL-2 (B), IFN- $\gamma$ (C), TNF- $\alpha$ (D), IL-6 (E), IL-17 (F), and IL-10 (G) in culture supernatants. All the results were obtained from at least three independent experiments. Values are shown as the mean $\pm \mathrm{SD}$ ( $\mathrm{n}=6$ per group). ${ }^{*} \mathrm{P}<0.05$, ${ }^{* *} \mathrm{P}<0.01$, and ${ }^{* * *} \mathrm{P}<0.001$ vs. Con $\mathrm{A}+/ 0 \mu M$ group. CFSE, carboxy-fluorescein diacetate succinimidyl ester; CBA, cytometric bead array; SD, standard deviation. 